Abstract to be submitted to:

Session H33: Preferential Flow, Transport, and Numerical Simulation in Variably

Saturated Multiphase Subsurface Systems

\title{
Initiation and Persistence of Preferential Flow in Fractured Rock
}

\section{Rohit Salve, Teamrat A. Ghezzehei, and Robert Jones}

To better understand preferential flow in fractured rock, we carried out an in situ field experiment in the underground Exploratory Studies Facililty in the fractured Topopah Spring tuff at Yucca Mountain, Nevada. Ponded water (with a $\sim 0.04 \mathrm{~m}$ head) was released onto a $3 \times 4 \mathrm{~m}^{2}$ infiltration plot (divided into 12 square subplots) over a period of $\sim 800$ days. As water was released, spatial and temporal variability in infiltration rates was continuously monitored. In addition, changes in moisture content were monitored along horizontal boreholes located in the formation $\sim 19-22 \mathrm{~m}$ below. This experiment revealed peculiar infiltration patterns. In particular, we observed that in some of the subplots, the infiltration rate abruptly increased a few weeks into the infiltration tests before gradually decreasing, while in others a relatively low infiltration rate persisted for the duration of the experiment. Distinct flow zones, varying in flow velocity, wetted cross-sectional area, and extent of lateral movement, intercepted the monitoring boreholes. There was also evidence of water being diverted above the ceiling of a cavity in the immediate vicinity of the monitoring boreholes. Observations from this field experiment suggest that isolated conduits, each encompassing a large number of fractures, develop within the fractured rock formation to form preferential flow paths that persist if there is a continuous supply of water. An overriding conclusion is that field investigations at spatial scales of tens of meters provide data critical to the fundamental understanding of preferential flow in fractured rock.

This work was supported by the Director, Office of Civilian Radioactive Waste Management, U.S. Department of Energy, through Memorandum Purchase Order EA9013MC5X between Bechtel SAIC Company, LLC, and the Ernest Orlando Lawrence Berkeley National Laboratory (Berkeley Lab). The support is provided to Berkeley Lab through the U.S. Department of Energy Contract No. DE-AC02-05CH11231. 